Herbert Schneider (Saarbrücken)

\title{
Zum Gedenken an Hellmut Federhofer (1911-2014)
}

Am 1. Mai 2014 ist Hellmut Federhofer nach kurzer Krankheit in Mainz verstorben. Am 6. August 1911 in Graz geboren, erhielt er eine gründliche pianistische (zuletzt bei dem Rubinstejn- und Liszt-Schüler Emil von Sauer) und musiktheoretische Ausbildung (bei Richard Stöhr, Alban Berg und Oswald Jonas) und erwarb 1934 das Kapellmeisterdiplom. Sein Studium der Musikwissenschaft bei Alfred Orel und Robert Lach in Wien schloss er mit der Dissertation Akkordik und Harmonik in den frühen Motetten der Trienter Kodices ab. Während seiner Tätigkeit im österreichischen Bibliothekarsdienst habilitierte er sich 1944 bei Werner Danckert an der Universität Graz mit der Schrift Musikalische Form als Ganzheit und leitete das dortige Musikwissenschaftliche Institut von 1949 bis 1959 zunächst ehrenamtlich, dann bis 1962 als außerordentlicher Professor. Den Mainzer Lehrstuhl für Musikwissenschaft bekleidete er von 1962 bis zur Emeritierung 1979 und war viele Jahre Herausgeber der von ihm initiierten Mainzer Studien der Musikwissenschaft.

In Graz hatte er bereits als Mitglied der Gesellschaft zur Herausgabe der Denkmäler der Tonkunst in Österreich gewirkt, die österreichische RISM-Arbeitsstelle und die Reihe Musik Alter Meister begründet sowie eine immense Zahl von Musikhandschriften und -drucken gesammelt, die im Diözesan-Archiv und in der Universität in Graz aufbewahrt werden. Die Gebiete seines umfangreichen Schaffens, das er die Gnade hatte, bis im Alter von fast 103 Jahren fortzusetzen, umspannt die Epochen von der Renaissance bis in die Gegenwart, die Gebiete der Musiktheorie, der Edition, die Musikpflege, insbesondere am Grazer Hof und der Neuen Musik. Als Schüler von Jonas war er der Doyen der Schenker-Forschung, der mit seinen Arbeiten Maßstäbe gesetzt hat. Federhofer hat eine große Bandbreite von Problematiken und von historischen Fragen behandelt, auf dem Gebiet der Musiktheorie weit über Schenker hinaus. Mit Albert Wellek verband ihn die tiefe Sorge um Wahrnehmung, Hörbarkeit, Sinngehalt und ästhetischen Wert der zeitgenössischen Musik und deren gesellschaftliche Begleiterscheinungen. Trotz der zeitweiligen Anfeindungen, die seine Publikationen auf diesem Gebiet hervorriefen, wies er unerschrocken auf Missstände hin. Für ihn musste das Kunstwerk seine Deutung in sich tragen, diese sollte nicht von außen an es herangetragen werden. Auch wer seine kritischen Stellungnahmen, besonders zur Musik der 1960er und 1970er Jahre, nicht teilt, wird die Schärfe seiner Analysen anerkennen. Er ging den Fragen immer auf den Grund, die großen Synthesen und theoretischen Konzepte waren nicht seine Sache. Seine wissenschaftlichen Editionen reichen von Johannes de Cleve über die Mozart-Gesamtausgabe bis zur Fux-Gesamtausgabe, die ihm ein Herzensanliegen war und deren Editionsleitung er von 1955 bis 1967 und erneut von 1986 bis 2006 innehatte. Nicht weniger als 24 Jahre war er Herausgeber von Acta Musicologica und wurde dafür von der Internationalen Gesellschaft für Musikwissenschaft zum Ehrenmitglied ernannt. Er gehörte seit 1979 der Österreichischen Akademie der Wissenschaften als korrespondierendes Mitglied an. Kollegen und seine zahlreichen Schüler ehrten ihn mit drei Festschriften (1971 und 1998, 2011), von denen ihm die letzte zu seinem 100. Geburtstag überreicht wurde. Bis zuletzt hat er die Entwicklung seines Faches, der zeitgenössischen Musik und seines Instituts in Mainz mit wachem Geist verfolgt. 